\title{
Retraction Note: Agricultural climate change and agricultural economic sustainability based on resource scheduling algorithm
}

\author{
Xiang He ${ }^{1} \cdot$ Linna Dong $^{2} \cdot$ Jun Huang ${ }^{3} \cdot \mathrm{Kai} \mathrm{Hu}^{1}$
}

Published online: 6 December 2021

C) Saudi Society for Geosciences 2021

Retraction Note: Arabian Journal of Geosciences (2021) 14: 1492 https://doi.org/10.1007/s12517-021-07709-9

The Editor-in-Chief and the Publisher have retracted this article because the content of this article is nonsensical. The peer review process was not carried out in accordance with the Publisher's peer review policy. Authors Xiang He, Jun Huang and Kai Hu have not responded to correspondence regarding this retraction. The Publisher has not been able to obtain a current email address for author Linna Dong.

The original article can be found online at https://doi.org/10.1007/ s12517-021-07709-9.

$\mathrm{Kai} \mathrm{Hu}$

1992a11b11c@163.com

1 School of Economics and Management, Jiangxi Agricultural University, Nanchang 330045, China

2 Nanchang Business College, Jiangxi Agricultural University, Gongqingcheng 332020, China

3 School of Wealth Management, Nanchang Institute of Science and Technology, Nanchang 330108, China 